\title{
The economic burden of cancer care in Canada: a population-based cost study
}

\author{
Claire de Oliveira MA PhD, * Sharada Weir MA DPhil, ${ }^{*}$ Jagadish Rangrej MSc MMath, \\ Murray D. Krahn MD MSc, Nicole Mittmann MSc PhD, Jeffrey S. Hoch MA PhD, \\ Kelvin K.W. Chan MD PhD, Stuart Peacock MSc DPhil
}

Abstract

Background: Resource and cost issues are a growing concern in health care. Thus, it is important to have an accurate estimate of the economic burden of care. Previous work has estimated the economic burden of cancer care for Canada; however, there is some concern this estimate is too low. The objective of this analysis was to provide a comprehensive revised estimate of this burden.

Methods: We used a case-control prevalence-based approach to estimate direct annual cancer costs from 2005 to 2012 . We used patient-level administrative health care data from Ontario to correctly attribute health care costs to cancer. We employed the net cost method (cost difference between patients with cancer and control subjects without cancer) to account for costs directly and indirectly related to cancer and its sequelae. Using average patient-level cost estimates from Ontario, we applied proportions from national health expenditures data to obtain the economic burden of cancer care for Canada. All costs were adjusted to 2015 Canadian dollars.

Results: Costs of cancer care rose steadily over our analysis period, from $\$ 2.9$ billion in 2005 to $\$ 7.5$ billion in 2012 , mostly owing to the increase in costs of hospital-based care. Most expenditures for health care services increased over time, with chemotherapy and radiation therapy expenditures accounting for the largest increases over the study period. Our cost estimates were larger than those in the Economic Burden of Illness in Canada 2005-2008 report for every year except 2005 and 2006.

Interpretation: The economic burden of cancer care in Canada is substantial. Further research is needed to understand how the economic burden of cancer compares to that of other diseases.

ancer and related costs are increasing at a fast pace. ${ }^{1}$ Those who fund and organize cancer care struggle to provide patients with the latest treatments, given limited financial resources. Thus, it is important to have accurate cost estimates. ${ }^{2}$ Cost-of-illness studies can help translate the adverse effects of diseases into dollars, useful information for decision-makers. These estimates can be used to help set priorities for treatments and aid in the allocation of scarce resources within the health care sector. However, to our knowledge, few investigators have attempted to estimate the cost of cancer care for Canada.

Previous work estimated the direct economic burden of cancer care from diagnosis to survivorship/death but only for selected provinces and health services. ${ }^{3,4}$ The Public Health Agency of Canada report Economic Burden of Illness in Canada $2005-2008^{5}$ (EBIC) is a comprehensive cost-of-illness study that provides estimates of direct (e.g., medical expenditures) and indirect (e.g., lost productivity) costs for cancer for Canada.
It attributed health care expenditures to cancer by applying estimates of use patterns from various sources to aggregate data on health care spending by 3 expenditure categories: hospital care, physician care, and public and private drugs. Other direct health care expenditures (e.g., other professionals, capital and public health) were also included but could not be attributed to cancer. Furthermore, costs of other relevant cancer-related care, such as chemotherapy and radiation therapy,

Competing interests: None declared.

This article has been peer reviewed.

Correspondence to: Claire de Oliveira, claire.deoliveira@ camh.ca ${ }^{*}$ Claire de Oliveira and Sharada Weir both fulfill the role of first author.

CMAJ Open 2018. DOI:10.9778/cmajo.20170144 
were not captured. As such, the EBIC report underestimates the actual burden of cancer care. The purpose of the current study was to produce a more accurate estimate of the direct economic burden of cancer care for Canada using a more comprehensive approach.

\section{Methods}

\section{Setting}

We took a comprehensive approach to estimate the direct economic burden of cancer care for Canada using cancer prevalence rates, Ontario patient-level cost data and national expenditure data. For comparability with prior work, we examined 2 analysis periods: 2005-2008 (to provide more accurate revised estimates) and 2009-2012 (to provide more recent estimates). We estimated costs along the care continuum, from diagnosis to treatment to rehabilitation to survivorship to palliative care, including pain management (where possible).

\section{Study design}

We used a case-control prevalence-based approach to estimate direct costs for each year of our analysis periods. The 10-year person-based prevalence approach used to define our cohort was roughly in line with Statistics Canada's cancer prevalence reports. ${ }^{6}$ We estimated total and per-patient net costs of cancer care for Ontario and extrapolated them to the rest of Canada using relative provincial/territorial expenditures obtained from the National Health Expenditure Database (NHEX). ${ }^{7}$

\section{Data sources}

We obtained cancer prevalence rates from Statistics Canada and the Canadian Cancer Society. We used patient-level data from Ontario to estimate direct costs from the perspective of the third-party public payer (Ministry of Health and LongTerm Care). These data were accessed through the Institute for Clinical Evaluative Sciences, which houses comprehensive, linkable health care records for Ontario. Table 1 provides a list of all data sets used for this study. A full description of each data set can be found elsewhere. ${ }^{8}$ We used the NHEX to obtain provincial/territorial expenditures by health care category. ${ }^{7}$

\section{Analysis}

\section{Patient-level}

Identification of patients with cancer or in remission (case subjects): We used the Ontario Cancer Registry to select all patients with cancer and those in remission (case subjects) in whom cancer was diagnosed in the 10 years up to and including the year of analysis (see Supplementary Table S2 in Appendix 1, available at www.cmajopen.ca/content/6/1/E1/suppl/DC1, for a list of neoplasm codes included). We excluded all patients who were ineligible for public health care insurance or had missing data on sex.

Selection of patients without cancer (control subjects): We obtained patients without cancer (control subjects) from the Registered Persons Database, a population-based registry in
Ontario that includes demographic information and date of death for all Ontario residents. Potential control subjects were excluded if they were ineligible for public health care insurance, had missing data on sex or had a cancer diagnosis (with the exception of nonmelanoma skin cancer) before or during the full study period.

Matching of case and control subjects: We matched case subjects to control subjects on age within 2 years, sex and comorbidity (measured with the use of Aggregated Diagnosis Groups from the Johns Hopkins Adjusted Clinical Groups software ${ }^{9}$ excluding the malignant neoplasm cluster) at the start of each analysis period (2005 and 2009). Case subjects who died were matched to control subjects who died during the same year.

Estimation of costs: We linked case and control subjects to comprehensive administrative health care records using unique encrypted identifiers. We estimated patient-level costs using a cost algorithm available at the Institute for Clinical Evaluative

\begin{tabular}{|lc|}
\hline \multicolumn{2}{|l}{ Table 1: Databases available at the Institute for Clinical } \\
Evaluative Sciences
\end{tabular}


Sciences ${ }^{8}$ that includes the costs of inpatient hospital stays (acute and psychiatric); emergency department visits, same-day surgery, other ambulatory care; other institution-based care (e.g., rehabilitation, complex continuing care and long-term care); physician-related visits; outpatient prescription drugs (for those covered under the public provincial drug plan); $;^{10}$ nonphysician billings covered under the Ontario Health Insurance Plan (e.g., physiotherapists, optometrists, chiropractors); diagnostic tests; home care; and assistive devices. For comparability with prior work, ${ }^{5}$ we assigned costs to 3 categories: hospital care (which included hospital and other institution-based care), physician care and drugs. We also created a fourth category, "other care," which included the remaining health care services (nonphysician billings, diagnostic tests, home care and assistive devices).

To estimate the cost of parenteral and oral chemotherapy, we used the number of chemotherapy doses and unit drug costs available in Cancer Care Ontario's New Drug Funding Program database (cost incurred by the hospital) and the Ontario Drug Benefit claims database (cost incurred by the ministry of health), respectively. To estimate the cost of radiation therapy, we used the unit measure provided by the National Hospital Productivity Improvement Program codes in Cancer Care Ontario's Activity Level Reporting database and multiplied each unit by a unit cost estimate obtained from the literature. ${ }^{11}$

Data on some health care services were missing for some months/years, namely for psychiatric hospital admissions for the first 9 months of 2005, other ambulatory care (cancer clinic and dialysis visits) for 2005 and assistive devices from August 2010 onward. To address this, we extrapolated missing cost estimates for other ambulatory care and created annualized cost estimates for psychiatric inpatient hospital stays and assistive devices.

Calculation of net costs: We calculated aggregated gross perpatient costs for each cost category, sex and age group. To estimate the "true" costs due to cancer, we took a net cost approach, ${ }^{12,13}$ which has been used in previous work. ${ }^{3,14,15}$ This method consists of estimating the total gross cost of all health care resources used to treat case and control subjects by matching them on variables believed to influence use of these resources, such as sex, age and comorbidity. ${ }^{3,14}$ Mathematically, $N C=C^{P}-C^{C}$, where $\mathrm{NC}$ is net cost, $\mathrm{C}$ is gross cost and superscripts $\mathrm{P}$ and $\mathrm{C}$ denote patients (case subjects) and control subjects, respectively. The corresponding variance was defined as $\operatorname{Var}(N C)=\operatorname{Var}\left(C^{P}\right)+\operatorname{Var}\left(C^{C}\right)$, where the covariance of costs for patients (case subjects) and control subjects was assumed to be independent, given the conditional independence of the demographic variables and comorbidity after matching. In addition, 95\% confidence intervals (CIs) were produced for each cost estimate through Taylor series expansion based on asymptotic assumptions. ${ }^{16}$

\section{National-level}

Identification of person-based cancer prevalence: Person-based cancer prevalence rates were not available by province/territory; rates by sex were available for Canada for 2005, 2007 and
2009 only ${ }^{17-19}$ We used linear interpolation to obtain prevalence rates by sex for 2006 and 2008, and extrapolation for 2010-2012. We used existing 10-year tumour-based prevalence rates by sex and age group ${ }^{19}$ to infer the corresponding person-based prevalence rates. To estimate the number of people living with cancer, we applied the Canadian prevalence rate in each province/territory and multiplied our sex and age group prevalence estimates by the corresponding population group of each province/territory obtained from the NHEX. ${ }^{7}$ (Further details can be found in Appendix 1.)

Calculation of costs: To estimate aggregate national-level costs, we used NHEX data to create extrapolation factors for each cost category to reflect differences in relative expenditures between Ontario and the other provinces/territories (methodological details can be found in Appendix 1). Extrapolation factors for "other care" were based on expenditure data for "other professionals"; this was the category that best matched the mix of health care services included in the "other expenditures" category. We used hospital care extrapolation factors for chemotherapy and radiation therapy. Missing data for some provinces and analysis periods were replaced with similar regional provincial data for the same year and cost category, where required.

All analyses were done by sex (male/female) and age group ( $\leq 14 \mathrm{yr}, 15-34 \mathrm{yr}, 35-54 \mathrm{yr}, 55-64 \mathrm{yr}, 65-74 \mathrm{yr}$ and $\geq 75 \mathrm{yr}$ ), as defined in previous work. ${ }^{5}$ Cost estimates were expressed in constant 2015 dollars with the use of the provincial health care component of the Consumer Price Index produced by Statistics Canada. ${ }^{20}$ We performed all analyses using SAS version 9.3 (SAS Institute) and Microsoft Excel (2010).

\section{Ethics approval}

This study was approved by the Research Ethics Board at Sunnybrook Health Sciences Centre, Toronto.

\section{Results}

\section{Patient-level net costs}

We found matches for $95.8 \%$ of our case subjects, overall, in both analysis periods (Table 2). Over $99 \%$ of patients who were alive during each period were matched; for patients who had died, just over $80 \%$ were matched. There were no significant differences after matching between case and control subjects on age, sex or comorbidity in either analysis period or cohort.

Table 3 and Table 4 provide total net cost estimates in constant 2015 dollars by cost category for 2005-2008 and 2009-2012, respectively (corresponding total gross cost estimates can be found in Appendix 1). Total net costs increased over both analysis periods, from $\$ 1024.5$ million (95\% CI $\$ 997.2$ million to $\$ 1051.9$ million) in 2005 to $\$ 2073.0$ million (95\% CI \$2034.3 million to \$2111.7 million) in 2008, and from $\$ 1825.4$ million $(95 \%$ CI $\$ 1785.9$ million to $\$ 1864.9$ million) in 2009 to $\$ 2610.4$ million (95\% CI $\$ 2568.5$ million to $\$ 2652.2$ million) in 2012. Subcategories of net costs were negative for some years owing to higher costs among control subjects. 


\begin{tabular}{|c|c|c|c|c|}
\hline Study period; status & $\begin{array}{l}\text { No. of } \\
\text { eligible case } \\
\text { subjects }\end{array}$ & $\begin{array}{c}\text { No. }(\%) \text { of case } \\
\text { subjects matched }\end{array}$ & $\begin{array}{l}\text { No. of } \\
\text { unique } \\
\text { control } \\
\text { subjects }\end{array}$ & $\begin{array}{c}\% \text { of } \\
\text { control } \\
\text { subjects } \\
\text { matched } \\
\text { more than } \\
\text { once }\end{array}$ \\
\hline \multicolumn{5}{|l|}{ 2005-2008 } \\
\hline Alive during study period & 472468 & $470620(99.6)$ & & \\
\hline Died during study period & 138611 & $114354(82.5)$ & & \\
\hline Total & 611079 & 584974 (95.7) & 549124 & 6.1 \\
\hline \multicolumn{5}{|l|}{ 2009-2012 } \\
\hline Alive during study period & 557878 & $556349(99.7)$ & & \\
\hline Died during study period & 149636 & $121977(81.5)$ & & \\
\hline Total & 707514 & $678326(95.9)$ & 646694 & 4.7 \\
\hline
\end{tabular}

\section{National-level costs}

Figure 1 depicts total (net) public expenditures, in constant 2015 dollars, on cancer care by cost category and year for Canada. Total net expenditures rose substantially over both study periods, from $\$ 2.9$ billion in 2005 to roughly $\$ 7.5$ billion in 2012, mainly driven by hospital-based care (see Appendix 1 for total [net] public expenditures by cost category, sex and year). Although most expenditures for health care services increased over time, chemotherapy and radiation therapy expenditures saw the largest increases over the study period (by a factor of 3 and almost 4 times, respectively, from 2005 to 2012) (Figure 2).

Table 5 provides our estimates for each expenditure category (including our augmented hospital care and other care expenditures categories), from 2005 to 2008, alongside the EBIC report estimates, in constant 2015 dollars. Figure 3 illustrates these comparisons for 2008. The EBIC report estimate for 2008 was higher ( $\$ 4.2$ billion) than our net expenditure estimate ( $\$ 3.6$ billion), excluding chemotherapy, radiation therapy and other care; however, our estimate of hospital care was slightly higher than that in the EBIC report ( $\$ 2.6$ billion v. $\$ 2.5$ billion). When we included chemotherapy and radiation therapy, our total estimate increased to $\$ 4.5$ billion; it increased further to $\$ 4.9$ billion when we included other care.

\section{Interpretation}

We found that the economic burden of cancer care in Canada more than doubled over our entire analysis period, rising from $\$ 2.9$ billion in 2005 to $\$ 7.5$ billion in 2012. Hospital care expenditures made up the largest portion, followed by physician care and drug expenditures; other expenditures were of similar magnitude to that of drugs and thus not negligible.

Previous work on the economic burden of cancer has not been as comprehensive regarding costs included and has examined only $1^{3}$ or 2 provinces. ${ }^{4}$ Thus, our estimates are comparable only with those in the EBIC report, ${ }^{5}$ in particular for our first analysis period (2005-2008). We found higher total expenditures for 2007 (by 9\%) and 2008 (by $18 \%)$. Our estimates of hospital care expenditures were lower than those in the EBIC report, with the exception of 2008. However, when hospital care was expanded to include chemotherapy and radiation therapy, our estimate was higher for all years except 2005. Our findings suggest that the EBIC report likely underestimates the actual expenditures on hospital care for patients with cancer. Our physician care expenditures were lower than those in the EBIC report for all years. The EBIC report attributed physician care expenditures to specific conditions by applying patterns from Manitoba's publicly available fee-for-service data to total physician expenditure data in the NHEX. Costs may have been misattributed to cancer if patterns found in Manitoba's fee-for-service system did not apply to other provinces and payment systems. Our revised estimates of physician care were based on costs observed in Ontario, where the share of physicians paid fee-for-service was lower than in Quebec and the western provinces for most years of the full study period. ${ }^{21}$ Hence, our estimates of physician care expenditures may be biased downward. We could not compare our drug expenditures with those from the EBIC report. Our estimates included costs of outpatient prescription drugs and dispensing fees covered under public provincial/territorial drug plans only; those in the EBIC report included costs of outpatient prescription drugs covered under both public and private insurance plans and fees. Thus, our estimates are a portion of those included in the EBIC report. When we included all relevant costs, such as costs of home care and other health care services (likely nonattributable and thus not explicitly included in the EBIC report), our total cost estimates were larger than those in the EBIC report for every year except 2005 and 2006. When all relevant costs are considered, the true cost of caring for patients with cancer is likely higher than the estimates currently available. 
Table 3: Total net cost (in constant 2015 dollars) for patients with malignant neoplasms* diagnosed in the 10 years up to and including the year of analysis in Ontario, 2005-2008, by cost category

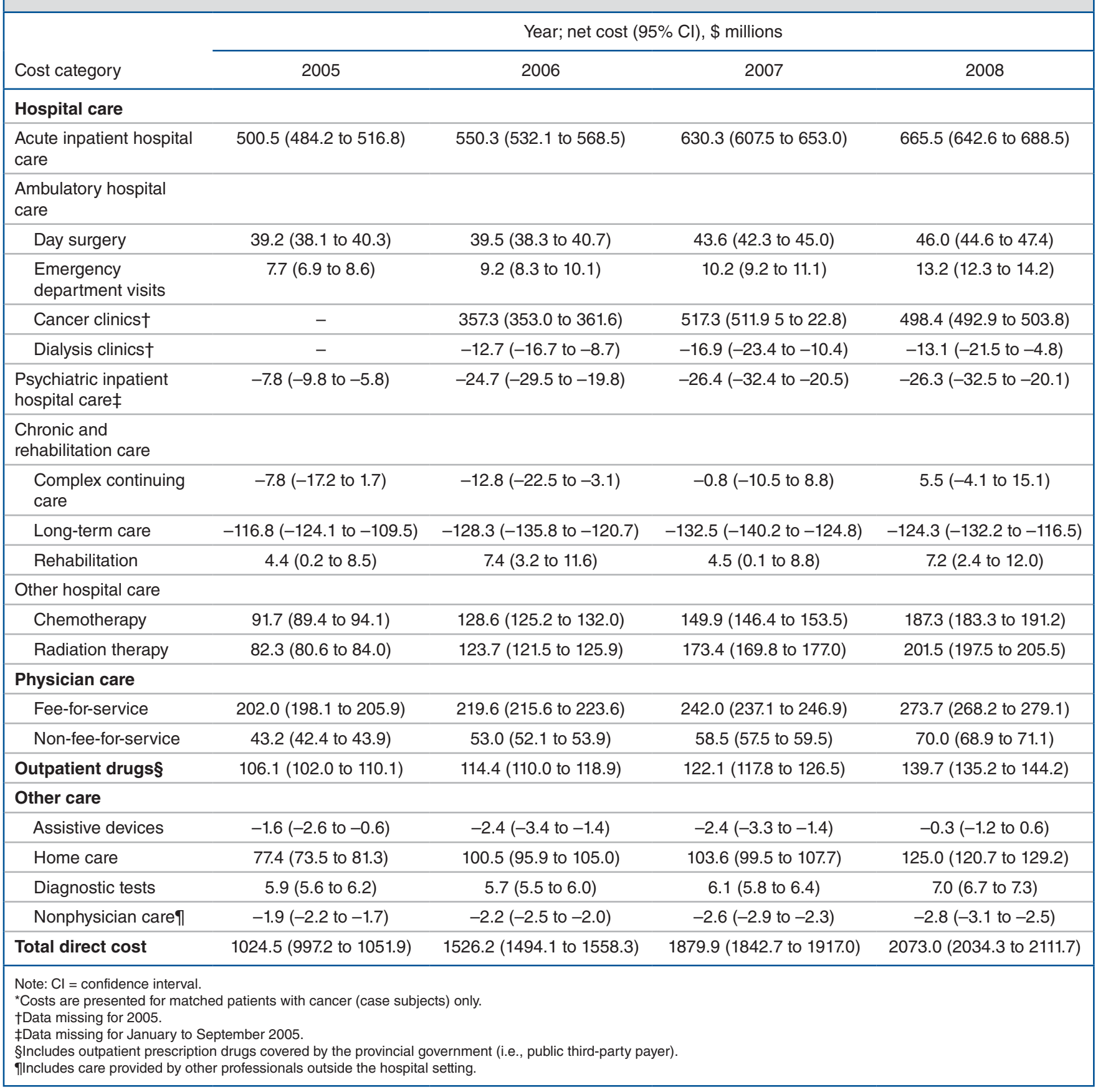

Our analysis used rich administrative health care data and a large population-based prevalence sample of children and adults in Ontario. This enabled us to attribute all direct costs to patients and cost categories, in contrast to previous work. The use of a case-control methodology enabled us to estimate costs directly and indirectly related to cancer and its sequelae, a more accurate measure of all relevant costs of care. It is vital to have accurate cost estimates. This information is important to stakeholders, such as third-party payers (i.e., ministries/departments of health), as they bear the direct (public) cost of treating patients with cancer. These estimates may be used to inform decisions regarding allocation of health care resources and to set future health care budgets. In particular, chemotherapy cost estimates will be of interest to members of the Canadian Association of Provincial Cancer Agencies and provincial/territorial ministries/departments of health, as the provision of cancer-related drugs has a direct impact on their budgets. These data may also be useful to the 
Table 4: Total net cost (in constant 2015 dollars) for patients with malignant neoplasms* diagnosed in the past 10 years in Ontario, 2009-2012, by cost category

\begin{tabular}{|c|c|c|c|c|}
\hline \multirow[b]{2}{*}{ Cost category } & \multicolumn{4}{|c|}{ Year; net cost $(95 \% \mathrm{Cl}), \$$ millions } \\
\hline & 2009 & 2010 & 2011 & 2012 \\
\hline \multicolumn{5}{|l|}{ Hospital care } \\
\hline $\begin{array}{l}\text { Acute inpatient hospital } \\
\text { care }\end{array}$ & 571.3 (547.2 to 595.3$)$ & 566.5 (542.6 to 590.3$)$ & 597.3 (573.4 to 621.2$)$ & 724.4 (700.4 to 748.5$)$ \\
\hline \multicolumn{5}{|l|}{$\begin{array}{l}\text { Ambulatory hospital } \\
\text { care }\end{array}$} \\
\hline Day surgery & 48.3 (46.9 to 49.7$)$ & 48.5 (47.1 to 49.9$)$ & 55.1 (53.7 to 56.5$)$ & $61.7(60.2$ to 63.2$)$ \\
\hline $\begin{array}{l}\text { Emergency } \\
\text { department visits }\end{array}$ & 9.5 (8.5 to 10.4$)$ & 8.8 (7.8 to 9.7$)$ & 11.2 (10.2 to 12.2$)$ & 16.8 (15.7 to 17.8$)$ \\
\hline Cancer clinics & 474.1 (468.5 to 479.8$)$ & 497.6 (491.6 to 503.7$)$ & 753.3 (744.5 to 762.2 ) & 783.2 (774.4 to 791.9$)$ \\
\hline Dialysis clinics & $-25.1(-33.4$ to -16.9$)$ & $-30.3(-39.2$ to -21.4$)$ & $-15.7(-21.8$ to -9.7$)$ & $-4.2(-10.5$ to 2.2$)$ \\
\hline $\begin{array}{l}\text { Psychiatric inpatient } \\
\text { hospital care }\end{array}$ & $-22.0(-27.9$ to -16.1$)$ & $-26.5(-32.7$ to -20.3$)$ & $-27.3(-33.7$ to -20.9$)$ & $-25.7(-32.5$ to -18.9$)$ \\
\hline \multicolumn{5}{|l|}{$\begin{array}{l}\text { Chronic and } \\
\text { rehabilitation care }\end{array}$} \\
\hline $\begin{array}{l}\text { Complex continuing } \\
\text { care }\end{array}$ & $-14.2(-24.1$ to -4.2$)$ & $-1.1(-11.2$ to 9.0$)$ & $-0.5(-10.4$ to 9.4$)$ & 14.3 (4.3 to 24.2$)$ \\
\hline Long-term care & $-139.9(-147.7$ to -132.0$)$ & $-148.9(-157.7$ to -140.1$)$ & $-149.4(-158.5$ to -140.4$)$ & $-121.8(-130.8$ to -112.8$)$ \\
\hline Rehabilitation & 5.8 (1.4 to 10.2$)$ & $4.9(-0.8$ to 10.7$)$ & $6.0(1.3$ to 10.7$)$ & $13.4(8.2$ to 18.6$)$ \\
\hline \multicolumn{5}{|l|}{ Other hospital care } \\
\hline Chemotherapy & $172.0(168.2$ to 175.8$)$ & $186.4(182.3$ to 190.5$)$ & $194.3(190.1$ to 198.6$)$ & 212.5 (208.0 to 217.1$)$ \\
\hline Radiation therapy & $185.0(181.2$ to 188.7$)$ & 201.0 (197.1 to 205.0$)$ & 234.1 (229.9 to 238.4) & 240.8 (236.4 to 245.2 ) \\
\hline \multicolumn{5}{|l|}{ Physician care } \\
\hline Fee-for-service & 242.6 (237.9 to 247.3$)$ & 260.8 (256.7 to 264.8$)$ & 287.5 (283.5 to 291.6$)$ & 314.8 (310.7 to 318.9$)$ \\
\hline Non-fee-for-service & 71.9 (68.4 to 75.5$)$ & 60.7 (59.8 to 61.7$)$ & 41.8 (41.1 to 42.2 ) & 50.0 (49.3 to 50.8$)$ \\
\hline Outpatient drugs $†$ & $136.8(132.0$ to 141.6$)$ & 147.6 (141.9 to 153.3$)$ & $159.0(152.9$ to 165.1$)$ & 190.6 (184.0 to 197.3$)$ \\
\hline \multicolumn{5}{|l|}{ Other care } \\
\hline Assistive devices $\ddagger$ & $-2.8(-3.6$ to -2.0$)$ & $-0.8(-1.1$ to -0.4$)$ & - & - \\
\hline Home care & 108.3 (103.8 to 112.8$)$ & 107.8 (103.1 to 112.5$)$ & $118.9(113.7$ to 124.0$)$ & 136.3 (131.3 to 141.3$)$ \\
\hline Diagnostic tests & $6.8(6.5$ to 7.1$)$ & $6.4(6.2$ to 6.7$)$ & $6.3(6.0$ to 6.5$)$ & $6.8(6.5$ to 7.0$)$ \\
\hline Nonphysician care & $-3.0(-3.3$ to -2.6$)$ & $-3.7(-4.1$ to -3.4$)$ & $-3.9(-4.2$ to -3.5$)$ & $-3.6(-4.0$ to -3.2$)$ \\
\hline Total direct cost & 1825.4 (1785.9 to 1864.9$)$ & $1885.7(1845.4$ to 1926.0$)$ & 2268.1 (2227.0 to 2309.2) & 2610.4 (2568.5 to 2652.2 ) \\
\hline $\begin{array}{l}\text { Note: } \mathrm{Cl}=\text { confidence interv } \\
{ }^{*} \text { Costs are presented for ma } \\
\text { †lncludes outpatient prescri } \\
\text { †Data missing from Septem }\end{array}$ & $\begin{array}{l}\text { tients with cancer (case subje } \\
\text { gs covered by the provincial } g \\
\text { onward. }\end{array}$ & $\begin{array}{l}\text { only. } \\
\text { nment (i.e., public third-party } p\end{array}$ & & \\
\hline
\end{tabular}

pan-Canadian Pharmaceutical Alliance to inform future drug price negotiations.

\section{Limitations}

Our analysis has some limitations. Prevalence rates were missing for some years of our study, which necessitated extrapolation. Furthermore, these rates were not available by province/ territory; thus, we assumed the same prevalence rate across all jurisdictions. We also made several assumptions to extrapolate person-based prevalence from tumour-based prevalence for each sex/age group. These extrapolations/assumptions likely affected the actual number of cancer cases, although it is not clear in which direction. Although we estimated costs from diagnosis to survivorship/death, we did not include the costs of screening and diagnosis ascertainment, as it was not feasible to estimate this for every case. Our cost estimates are likely conservative in other respects as well. First, our patient-level data were limited to costs paid by the Ontario Ministry of Health and Long-Term Care, which includes roughly $91 \%$ of government-related health care costs. ${ }^{22} \mathrm{We}$ were able to capture only third-party public costs for outpatient prescription drugs and dispensing fees; in Ontario, this includes patients 


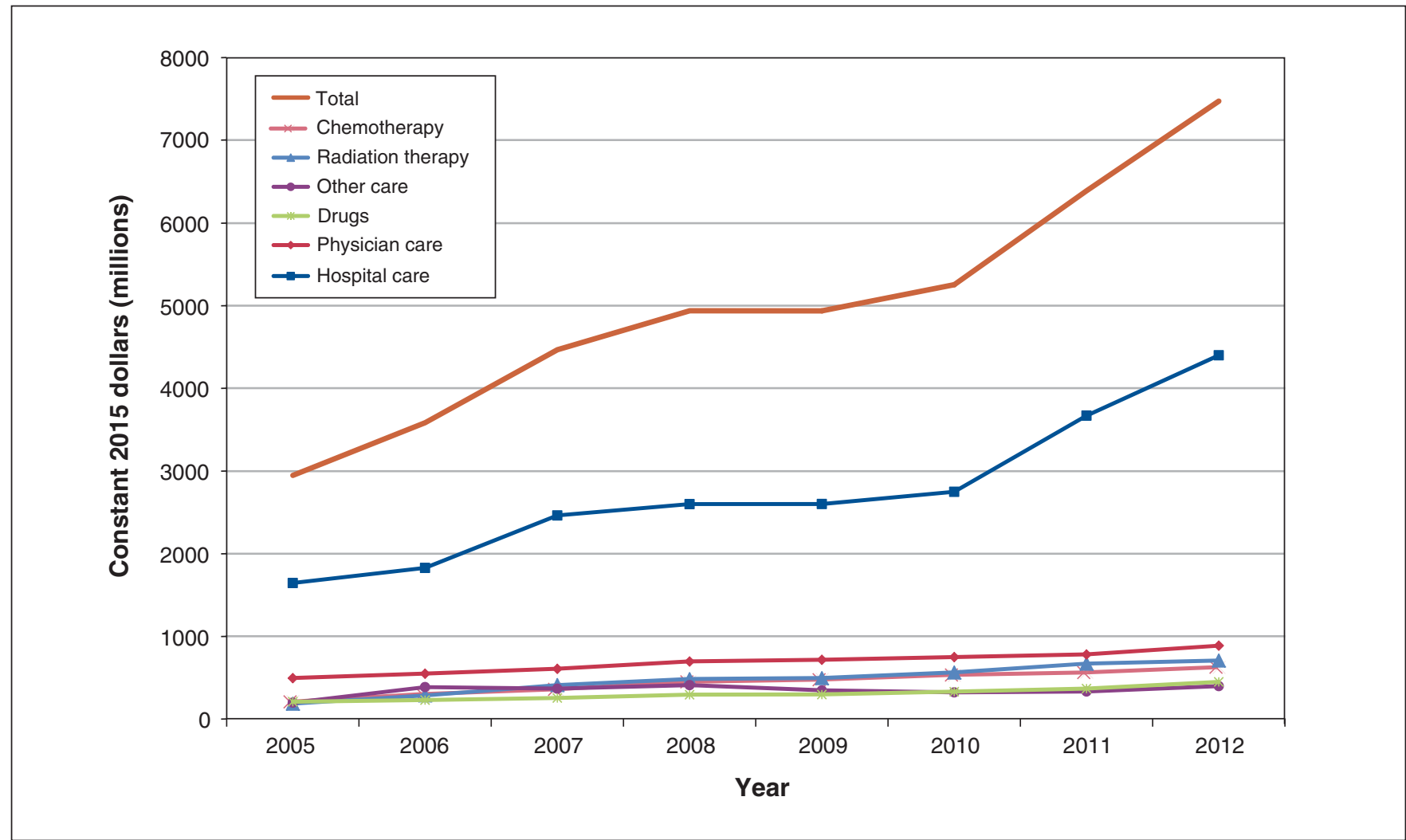

Figure 1: Total (net) public expenditures (in constant 2015 dollars) on cancer care in Canada, 2005-2012, by cost category. Case subjects were matched to control subjects in 2005 and 2009. "Other care" includes nonphysician care (including other professional services performed outside the hospital setting), diagnostic testing, home care and assistive devices.

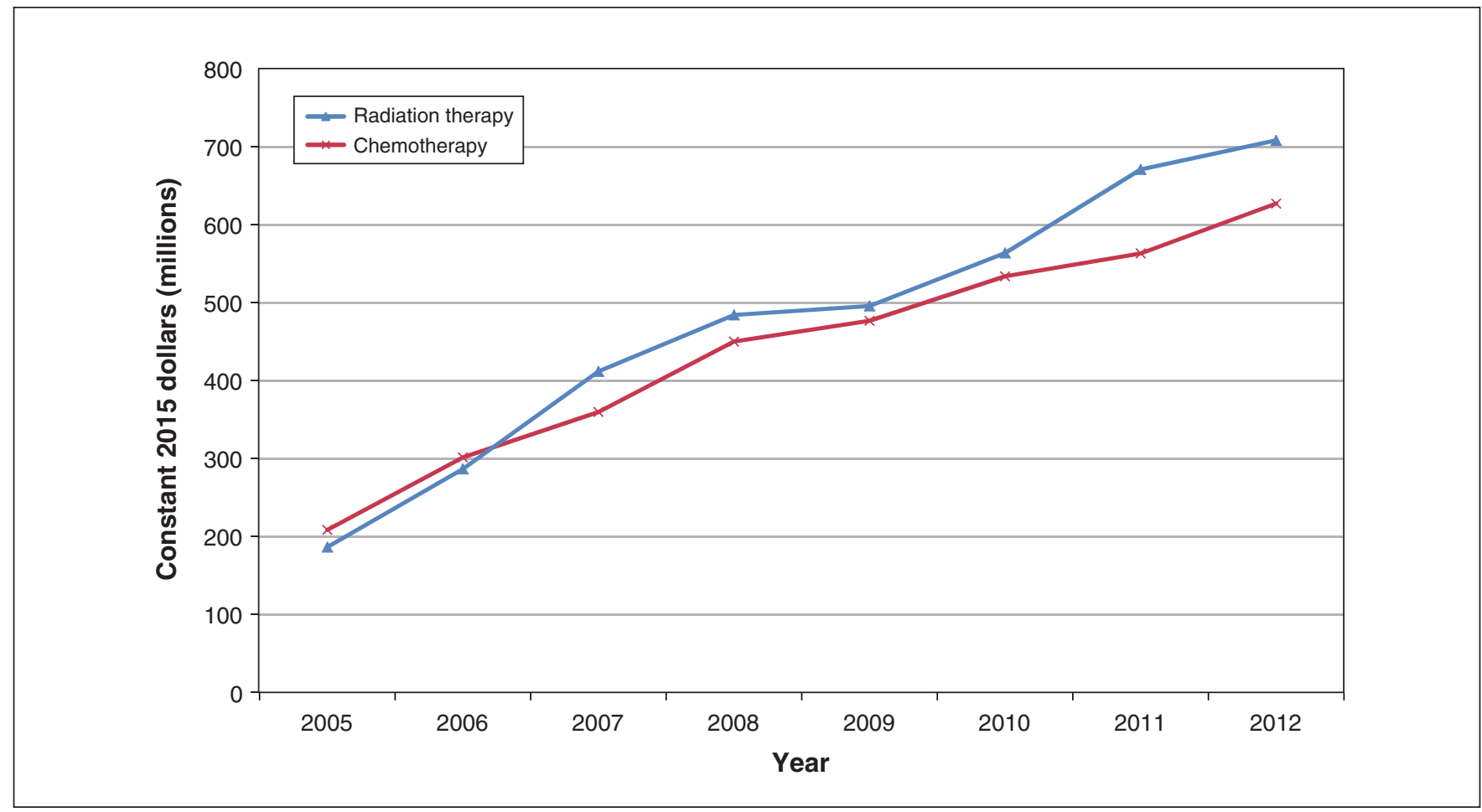

Figure 2: Total (net) public expenditures (in constant 2015 dollars) on radiation therapy and chemotherapy in Canada, 2005-2012. Case subjects were matched to control subjects in 2005 and 2009. 


\begin{tabular}{|c|c|c|c|c|}
\hline \multicolumn{5}{|c|}{$\begin{array}{l}\text { Table 5: Total public expenditures (in constant } 2015 \text { dollars) for cancer care in Canada, } \\
\text { 2005-2008, according to Economic Burden of IIIness in Canada 2005-2008 report }{ }^{5} \text { and } \\
\text { current revised estimates, by cost category }\end{array}$} \\
\hline \multirow[b]{2}{*}{ Source; cost category } & \multicolumn{4}{|c|}{ Year; cost, \$ millions } \\
\hline & 2005 & 2006 & 2007 & 2008 \\
\hline \multicolumn{5}{|l|}{ EBIC report estimates } \\
\hline Hospital care & 2267.5 & 2345.7 & 2504.9 & 2542.1 \\
\hline Physician care & 847.1 & 894.1 & 1027.2 & 1125.9 \\
\hline Outpatient drugs* & 408.5 & 625.2 & 560.7 & 509.8 \\
\hline \multicolumn{5}{|l|}{ Other care† } \\
\hline Total expenditures & 3523.2 & 3865.0 & 4092.9 & 4177.8 \\
\hline \multicolumn{5}{|l|}{ Revised estimates } \\
\hline Hospital care & 1645.7 & 1828.7 & 2463.1 & 2600.1 \\
\hline Chemotherapy & 208.8 & 301.7 & 360.0 & 450.3 \\
\hline Radiation therapy & 186.7 & 286.9 & 412.0 & 484.4 \\
\hline Physician care & 496.4 & 549.5 & 608.3 & 697.4 \\
\hline Outpatient drugs* & 209.9 & 230.4 & 255.5 & 295.0 \\
\hline Other care $\dagger$ & 199.5 & 387.0 & 368.0 & 410.9 \\
\hline $\begin{array}{l}\text { Total expenditures (excluding } \\
\text { chemotherapy, radiation therapy } \\
\text { and other care) }\end{array}$ & 2351.9 & 2608.7 & 3326.9 & 3592.5 \\
\hline $\begin{array}{l}\text { Total expenditures (including } \\
\text { chemotherapy and radiation } \\
\text { therapy) }\end{array}$ & 2747.5 & 3197.4 & 4098.8 & 4527.2 \\
\hline $\begin{array}{l}\text { Total expenditures (including } \\
\text { chemotherapy, radiation therapy } \\
\text { and other care) }\end{array}$ & 2947.0 & 3584.4 & 4466.8 & 4938.1 \\
\hline \multicolumn{5}{|l|}{$\begin{array}{l}\text { Difference: revised estimates } \\
\text { versus EBIC report estimates }\end{array}$} \\
\hline $\begin{array}{l}\text { Revised estimates excluding } \\
\text { chemotherapy, radiation therapy } \\
\text { and other care }\end{array}$ & -1171.2 & -1256.3 & -766.0 & -585.2 \\
\hline $\begin{array}{l}\text { Revised estimates including } \\
\text { chemotherapy and radiation } \\
\text { therapy but excluding other care }\end{array}$ & -775.7 & -667.7 & 5.9 & 349.4 \\
\hline $\begin{array}{l}\text { Revised estimates including } \\
\text { chemotherapy, radiation therapy } \\
\text { and other care }\end{array}$ & -576.2 & -280.6 & 374.0 & 760.3 \\
\hline \multicolumn{5}{|c|}{$\begin{array}{l}\text { Note: } \mathrm{EBIC}=\text { Economic Burden of IIIness in Canada } 2005-2008 \text {. } \\
\text { *Includes expenditures by both public and private insurance plans in the EBIC report estimates but includes only public } \\
\text { expenditures in the revised estimates. } \\
\text { †Includes nonphysician care (including other professional services performed outside the hospital setting), diagnostic } \\
\text { testing, home care and assistive devices. }\end{array}$} \\
\hline
\end{tabular}

aged 65 years or more and special cases (e.g., people receiving social assistance).$^{10}$ Data on outpatient prescription drugs paid by private health insurance plans were not available. Second, along with age and sex, we matched on comorbidity, which may have attenuated the higher risk of development of comorbid conditions among patients with cancer, leading to more conservative estimates. Third, to extrapolate the Ontario cost to other Canadian provinces/territories, we assumed that relative spending for patients with cancer (in each province/territory v. Ontario) reflected the relative total spending by provincial/territorial government payers for each cost category. However, some jurisdictions may be more or less generous in their cancer care spending, which would have affected our results. Given the lack of spending estimates for chemotherapy and radiation therapy, we used relative hospital care spending; this may have biased our national estimates downward. In addition, we assumed similar drug coverage for all provinces/territories, which may not be 


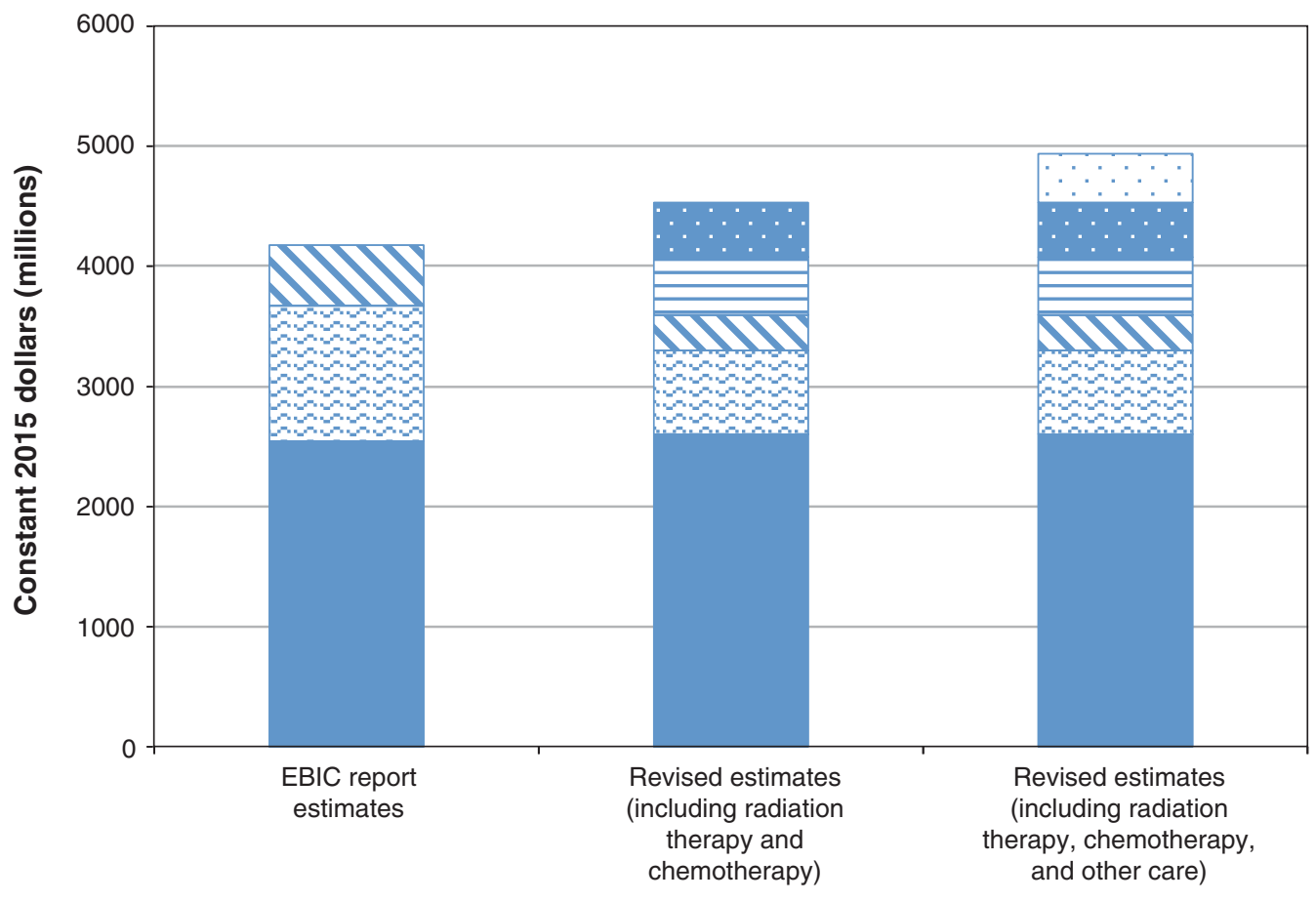

Hospital care $\square$ Physician care $\nabla$ Drugs $\boxminus$ Radiation therapy $\cdot$ Chemotherapy $\because$ Other care

Figure 3: Total public expenditures (in constant 2015 dollars) on cancer care in Canada, 2008, by cost category. "Drugs" includes expenditures by both public and private insurance plans in the EBIC report estimates but includes only public expenditures in the current revised estimates. "Other care" includes home care, nonphysician care (including other professional services performed outside the hospital setting), diagnostic testing and assistive devices. Note: EBIC = Economic Burden of IIIness in Canada 2005-2008. ${ }^{5}$

applicable to all Canadian jurisdictions (e.g., British Columbia). Data from the NHEX were missing for some categories and years for some jurisdictions, which required making assumptions to obtain imputed values. Furthermore, we were not able to find an equivalent cost category in the NHEX for "other expenditures." Finally, we estimated the direct costs incurred by the public third-party payer only; we did not have the data required to estimate other direct costs (e.g., out-ofpocket costs) or indirect costs (e.g., lost productivity associated with cancer).

\section{Conclusion}

Our analysis suggests that the economic burden of cancer care in Canada is larger than previously estimated. Hospital care made up the largest and fastest-growing share of the overall burden. In particular, chemotherapy and radiation therapy expenditures grew the most. Nevertheless, given our assumptions and data limitations, our values are likely an underestimate of the true economic burden. Future work is required to estimate the full cost of both prescription and nonprescription drugs covered by public and private third-party payers. Given that this analysis was based on cost estimates for Ontario only, the accuracy of national estimates would be improved by using province-specific cost data where possible. Further research is also needed to understand how the economic burden of cancer compares to that of other diseases.

\section{References}

1. National health expenditure trends, 1975 to 2011. Ottawa: Canadian Institute for Health Information: 2011.

2. Mittmann N, de Oliveira C. Importance of cost estimates and cost studies. Curr Oncol 2016;23(Suppl 1):S6.

3. de Oliveira C, Pataky R, Bremner KE, et al. Phase-specific and lifetime costs of cancer care in Ontario. BMC Cancer 2016;16:809.

4. de Oliveira C, Pataky R, Bremner KE, et al. Estimating the cost of cancer care in British Columbia and Ontario: a Canadian inter-provincial comparison. Healthc Policy 2017;12:95-108.

5. Economic burden of illness in Canada, 2005-2008. Ottawa: Public Health Agency of Canada; 2014. Cat. no. HP50-1/2013E-PDF. Available: https://www.canada. $\mathrm{ca} /$ content/dam/phac-aspc/migration/phac-aspc/publicat/ebic-femc/2005-2008/ assets/pdf/ebic-femc-2005-2008-eng.pdf (accessed 2016 Mar. 29).

6. Ellison LF, Wilkins K. Canadian trends in cancer prevalence. Ottawa: Statistics Canada; 2012. Cat. no. 82-003-XPE, Health Reports, Vol. 23, No. 1.

7. National Health Expenditures Database Metadata (NHEX). Ottawa: Canadian Institute for Health Information; 2016. Available: https://www.cihi.ca/en/ spending-and-health-workforce/spending/health-spending-data/national-health -expenditure-database (accessed 2016 Mar. 30).

8. Wodchis WP, Bushmeneva K, Nikitovic M, et al. Guidelines on person-level costing using administrative databases in Ontario. Working Paper Series Vol. 1. Toronto: Health System Performance Research Network; 2013. 
9. Mumford L, Starfield B, Steinwachs D, et al. ACGs: ambulatory care groupings for case-mix categorization. Final report for grant \#HS05505, National Center for Health Care Research/Health Care Technology Assessment. Baltimore: Johns Hopkins University; 1990. Available: http://acg. jhsph.org/index.php/the-acg-system-advantage/acgs (accessed 2016 Mar. 30).

10. Get coverage for prescription drugs: get help paying for prescription drugs when you qualify for the Ontario Drug Benefit program. Toronto: Ministry of Health and Long-Term Care; 2016. Available: www.health.gov.on.ca/en/ public/programs/drugs/programs/odb/odb.aspx (accessed 2016 Mar. 30).

11. Earle C, Coyle D, Smith A, et al. The cost of radiotherapy at an Ontario regional cancer centre: a re-evaluation. Crit Rev Oncol Hematol 1999;32:87-93.

12. Taplin SH, Barlow W, Urban N, et al. Stage, age, comorbidity, and direct costs of colon, prostate, and breast cancer care. 7 Natl Cancer Inst 1995;87: $417-26$.

13. Brown ML, Riley GF, Potosky AL, et al. Obtaining long-term disease specific costs of care: application to Medicare enrolees diagnosed with colorectal cancer. Med Care 1999;37:1249-59.

14. Yabroff KR, Lamont EB, Mariotto A, et al. Cost of care for elderly cancer patients in the United States. 7 Natl Cancer Inst 2008;100:630-41.

15. Krahn MD, Zagorski B, Laporte A, et al. Healthcare costs associated with prostate cancer: estimates from a population-based study. BfU Int 2010;105: $338-46$.

16. Stuart A, Ord K. Kendall's advanced theory of statistics. Vol. 1: Distribution theory. 6th ed. New York: Oxford University Press; 2010

17. Canadian Cancer Society's Steering Committee on Cancer Statistics. Canadian cancer statistics 2009. Toronto: Canadian Cancer Society; 2009. Available: www.cancer.ca/ /media/cancer.ca/CW/cancer\%20information/ cancer\%20101/Canadian\%20cancer\%20statistics/Canadian-Cancer-Statistics -2009-EN.pdf?la=en (accessed 2016 Mar. 29).

18. Canadian Cancer Society's Steering Committee on Cancer Statistics. Canadian cancer statistics 2011. Toronto: Canadian Cancer Society; 2011. Available: www.cancer.ca/ /media/cancer.ca/CW/cancer\%20information/ cancer\%20101/Canadian\%20cancer\%20statistics/Canadian-Cancer-Statistics -2011-EN.pdf?la=en (accessed 2016 Mar. 29).

19. Canadian Cancer Society's Steering Committee on Cancer Statistics. Canadian cancer statistics 2014. Toronto: Canadian Cancer Society; 2014. Available: www.cancer.ca/ /media/cancer.ca/CW/cancer\%20information/ cancer\%20101/Canadian\%20cancer\%20statistics/Canadian-Cancer-Statistics -2014--EN.pdf (accessed 2016 Mar. 29)

20. Consumer Price Index, health and personal care, by province (Canada) [table]. Ottawa: Statistics Canada; 2016. Available: www.statcan.gc.ca/tables-tableaux/ sum-som/101/cst01/econ161a-eng.htm (accessed 2016 Mar. 30).

21. National Physician Database metadata. Ottawa: Canadian Institute for Health Information; 2016. Available: https://www.cihi.ca/en/spending-and-health -workforce/health-workforce/national-physician-database-npdb-metadata (accessed 2016 Mar. 30).

22. Wodchis WP, Austin PC, Henry DA. A 3-year study of high-cost users of health care. CMAF 2016;188:182-8.
Affiliations: Centre for Addiction and Mental Health (de Oliveira); Institute for Health Policy, Management and Evaluation (de Oliveira, Krahn), University of Toronto; Institute for Clinical Evaluative Sciences (de Oliveira, Rangrej, Krahn, Hoch); Ontario Medical Association (Weir); Toronto Health Economics and Technology Assessment Collaborative (Krahn); Faculty of Pharmacy (Krahn), University of Toronto; Cancer Care Ontario (Mittmann, Chan), Sunnybrook Health Sciences Centre, Toronto, Ont.; University of California, Davis (Hoch), Davis, Calif.; Canadian Centre for Applied Research in Cancer Control (Chan), Cancer Care Ontario, Toronto, Ont.; Canadian Centre for Applied Research in Cancer Control (Peacock), British Columbia Cancer Agency; University of British Columbia (Peacock); Simon Fraser University (Peacock), Vancouver, BC

Contributors: Claire de Oliveira and Sharada Weir managed the overall project, conceptualized and designed the study, analyzed and interpreted the data, and drafted the manuscript. Both fulfill the role of first author. Murray Krahn, Nicole Mittmann, Jeffrey Hoch, Kelvin Chan and Stuart Peacock contributed to the conceptualization and design of the study and to data analysis and interpretation, and revised the manuscript critically for important intellectual content. Jagadish Rangrej selected the patient cohort and linked it with administrative health care data housed at the Institute for Clinical and Evaluative Sciences, carried out data analysis under the guidance of Claire de Oliveira and Sharada Weir, and revised the manuscript critically for important intellectual content. All of the authors gave final approval of the version to be published and agreed to be accountable for all aspects of the work.

Funding: This study received support from the Canadian Centre for Applied Research in Cancer Control, which is funded by the Canadian Cancer Society. Stuart Peacock is supported by the Leslie Diamond Chair in Cancer Survivorship at the Faculty of Health Sciences, Simon Fraser University. Murray Krahn is supported by the F. Norman Hughes Chair in Pharmacoeconomics at the Faculty of Pharmacy, University of Toronto.

Disclaimer: This study was supported by the Institute for Clinical Evaluative Sciences (ICES), which is funded by an annual grant from the Ontario Ministry of Health and Long-Term Care (MOHLTC). The opinions, results and conclusions reported in this article are those of the authors and are independent from the funding sources. No endorsement by ICES or the Ontario MOHLTC is intended or should be inferred.

Supplemental information: For reviewer comments and the original submission of this manuscript, please see www.cmajopen.ca/content/6/1/ E1/suppl/DC1. 